\title{
A ORKUTIZAÇÃO DAS MARCAS: DISPUTAS MIDIATIZADAS DE DISTINÇÃO E PERTENCIMENTO ENTRE AS CLASSES SOCIAIS
}

\author{
The orkutização of brands: Disputes mediatized of distinction and belonging \\ between social classes
}

\section{El orkutização de las marcas: Controversias mediatizadas del distinción y pertenencia entre clases sociales}

\author{
Alhen Rubens Silveira Damasceno ${ }^{1}$ \\ Rafael Grohmann ${ }^{2}$
}

\begin{abstract}
Resumo
O presente estudo visa entender como as classes estão em conflito no meio social e têm nas marcas o ápice dessas disputas distintivas midiatizadas. Tal fenômeno tem ligação com a distinção das marcas por um núcleo pequeno e elitista da sociedade versus a popularização por parte de uma camada que enxerga na aquisição das marcas de luxo um lugar ao sol na possibilidade de inserção e pertencimento dentro da sociedade. Buscamos compreender as relações de distinção e pertencimento e as classes.

Palavras-chave: comunicação, classes, distinção, marca, orkutização.
\end{abstract}

\begin{abstract}
This study aims to understand how the classes are in conflict in the social environment and have the distinctive brands the culmination of these disputes mediatized. This phenomenon is connected with the distinction of brands by a small, elite unit of society versus the popularization by a layer that sees the acquisition of luxury brands a place in the sun in the possibility of inclusion and belonging in society. We try to understand the relations of belonging and distinction and class.
\end{abstract}

Keywords: communication, classes, distinction, brand, orkutização.

\footnotetext{
${ }^{1}$ Doutorando em Ciências da Comunicação pela Escola de Comunicações e Artes da Universidade de São Paulo sob a orientação da Prof ${ }^{a}$ Dra Clotilde Perez. Publicitário formado pela Universidade Federal do Ceará. Membro do GESC ${ }^{3}$ - Grupos de Estudos Semióticos em Comunicação, Cultura e Consumo da ECA/USP. E-mail: alhenrubens@gmail.com

${ }^{2}$ Doutorando e Mestre em Ciências da Comunicação pela Universidade de São Paulo. Professor do curso de Jornalismo do FIAM-FAAM Centro Universitário (Complexo Educacional FMU) e do curso de pósgraduação lato-sensu em Mídias e Redes Sociais da Universidade Anhembi Morumbi. Membro do Centro de Pesquisas em Comunicação e Trabalho (CPCT-ECA/USP). E-mail: rafael-ng@uol.com.br
} 
A orkutização das marcas: Disputas midiatizadas de distinção e pertencimento entre as classes sociais

de Alhen Rubens Silveira Damasceno e Rafael Grohmann

\section{Resumem}

Este estudio tiene como objetivo comprender como las clases están en conflicto en el entorno social y tienen las marcas distintivas de la culminación de estas disputas mediatizada. Este fenómeno está relacionado con la distinción de marcas por parte de una pequeña unidad de élite de la sociedad frente a la popularización de una capa que ve a la adquisición de las marcas de lujo de un lugar bajo el sol en la posibilidad de la inclusión y la pertenencia a la sociedad. Buscamos entender las relaciones de pertenencia y distinción y clase.

Palabras-clave: comunicación, las clases, distinción, marca, orkutização.

\section{INTRODUÇÃO}

Em 1935, Walter Benjamin (2012) já dizia sobre a "aura" da obra de arte quando ninguém tinha acesso a ela. Quando ela se populariza, há a "perda da aura" em dois sentidos: a perda do encanto, por não haver mais o valor inédito, irrepetível e "distinto", mas por outro, pode ocorrer a democratização das obras de arte.

Este artigo se insere em um contexto onde a "perda da aura" se chama “orkutização" e as "marcas" são a forma midiatizada dessas obras de arte, em um Brasil marcado pela reconfiguração de estratos sociais, principalmente a partir do acesso a bens de consumo.

Para tanto, buscamos compreender: a) as relações entre comunicação e classes sociais em suas diferentes matrizes teóricas, buscando um entendimento sobre as lutas e disputas no contexto brasileiro atual; b) o que é a orkutização e, consequentemente, a orkutização das marcas; c) exemplos e indícios desta orkutização a partir das marcas ressignificadas pelas classes populares.

\section{COMUNICAÇÃO E CLASSES SOCIAIS: DISPUTAS MIDIATIZADAS E PRÁTICAS DISTINTIVAS}

O debate sobre classe social no campo comunicacional é hegemônico nos anos 70 do século passado, em um contexto marcado pela Guerra Fria (MATTELART; SIEGELAUB, 1979). Com a queda do Muro de Berlim e a chegada do século XXI, o 
A orkutização das marcas: Disputas midiatizadas de distinção e pertencimento entre as classes sociais

de Alhen Rubens Silveira Damasceno e Rafael Grohmann

conceito foi relegado ao segundo plano. Entretanto, conforme Murdock (2009: 33), "a classe pode ter sido abolida retoricamente em muitos textos, mas uma quantidade impressionante de evidência empírica confirma que ela permanece como uma força essencial para modelar a maneira como vivemos hoje".

Logicamente, as classes sociais sofrem mutações e alteram sua composição o tempo todo, como todos os fenômenos sociais, de acordo com o movimento histórico. $\mathrm{O}$ "burguês" e o "proletário" não deixam de existir só porque as pessoas não os chamam mais assim, ou porque não existe mais a figura clássica de Chaplin em "Tempos Modernos" aplicada às fábricas. O "novo espírito do capitalismo" (BOLTANSKI; CHIAPELLO, 2009), com a flexibilização, os novos processos tecnológicos e o trabalho em rede, traz uma nova roupagem à questão das classes sociais. Eagleton (2012: 135) afirma ser uma ilusão pensar "que só porque os presidentes de empresa hoje podem usar tênis, ouvir Rage Against the Machine e implorar a seus empregados para o chamarem de 'fofos', a classe social foi varrida da face da terra".

$\mathrm{Na}$ sociologia, há três matrizes teóricas para a compreensão das classes sociais: Karl Marx, Max Weber e Pierre Bourdieu. As diferentes matrizes nos ajudam a pensar em desenhos metodológicos diversos para a pesquisa em comunicação, muitas vezes utilizando um pouco de cada autor. Não há um consenso sobre a definição do conceito. Marx, por exemplo, "não oferece uma definição sistemática do conceito de classe (...). O capítulo destinado à teoria de classes no livro III do Capital é interrompido justamente quando Marx tratava de explicitar sua definição de classe" (SANTOS, 2002: $81)$.

$\mathrm{Na}$ perspectiva marxista, as relações de classe são determinadas pelas relações sociais de produção, considerando como fundamentais as relações de propriedade e a exploração. "A conceitualização de classe remete essencialmente à posição (objetiva e subjetiva) que os indivíduos ocupam no mundo da produção social" (ANTUNES, 2005: 103). Para Eagleton (2012: 134), "o marxismo não define classe em termos de estilo, status, renda, sotaque ou preferência pessoal de ornar as paredes com patos ou Degas": o mais importante é seu lugar no modo capitalista de produção.

O conceito de classe no marxismo (GROHMANN, 2013b) põe ênfase na dimensão das "lutas", não se pretendendo uma "sociologia classificatória das classes". "Lutas" é mesmo no plural, pois são diversas as lutas de classe na contemporaneidade, para Losurdo (2013), entendendo estes conflitos de maneira ampliada. Trata-se de uma 
A orkutização das marcas: Disputas midiatizadas de distinção e pertencimento entre as classes sociais

de Alhen Rubens Silveira Damasceno e Rafael Grohmann

concepção que nos auxilia a compreender, por exemplo, as disputas em torno da "orkutização das marcas"

Além disso, o conceito de classe no marxismo é relacional. Como diz Thompson (1987: 10), "não podemos ter amor sem amantes, nem submissão sem senhores rurais e camponeses". Dominantes só existem se há dominados. Esta visão nos ajuda a pensar a existência das diferentes classes sociais atualmente, onde se pergunta se o proletariado estaria por vias de desaparecer. "A classe operária não deixa de interessar aos marxistas no momento em que passa a desfrutar de banheiros dentro de casa ou possuir TV em cores. É seu lugar no modo capitalista de produção que constitui o ponto mais decisivo" (EAGLETON, 2012: 138).

Já na concepção weberiana, a classe está ligada a situações comuns de mercado. Ou seja, mais do que a posse de propriedade ou o lugar na produção, interessa à perspectiva weberiana como a posse de habilidades ou recursos "se convertem em recompensas como renda, segurança no emprego, expectativa de progresso, autoridade" (SANTOS, 2002: 81). Weber (1966) distingue "classe" e "status" como duas formas qualitativamente diferentes de estratificação social. Enquanto classe se refere às relações sociais na vida econômica, o status se relaciona com a honra social e aos estilos de vida. A questão do status tem sido trabalhada pela "sociologia do consumo" a partir das ideias do weberiano John Goldthorpe, a partir das relações entre "status social" e "consumo cultural", considerando o consumo de cinema, música, teatro, dança e artes visuais (CHAN, 2010)

Já Bourdieu (2007) desenvolveu uma noção ampliada de classe a partir de reapropriações das teorias marxistas e weberianas. A partir de subdivisões do conceito de capital em econômico, social, cultural e simbólico, define-se classe como o que resulta da diferenciação do chamado "volume global de capital", sendo traduzido a partir de dimensões como status, salário e prestígio social. Para ele, ainda, uma classe se define pelo lugar e valor que atribui aos dois sexos e a suas disposições constituídas socialmente (BOURDIEU, 1999). Jessé Souza (2011) ilustra essa posição:

Tomemos um professor universitário iniciante que ganhe $R \$ 6$ mil. Tomemos agora um trabalhador qualificado que monitora os robôs da Fiat, em Minas Gerais, que também ganhe algo em torno de $R \$ 6$ mil mensais. Todas as escolhas dessas pessoas vão ser, com muita probabilidade, distintas, desde a mulher que se escolhe, os amigos, o tempo de lazer, as roupas que se compram, o padrão de consumo, os livros que se leem etc. Quando muito, essas pessoas vão poder conversar sobre futebol entre si. Qual o sentido de dizer que essas pessoas são da mesma classe porque ganham um salário semelhante? Ajuda a nossa compreensão de alguma delas estabelecer esse tipo de 
A orkutização das marcas: Disputas midiatizadas de distinção e pertencimento entre as classes sociais

de Alhen Rubens Silveira Damasceno e Rafael Grohmann

relação? $O$ que esta concepção dominante sobre as classes em todas as ciências hegemônicas e em toda a esfera pública dos jornais e das TVs permite é "esquecer" e relegar às sombras o principal: que as classes sociais são formadas por "culturas de classe" muito diferentes entre si. Não existe "o" brasileiro, nem " $a$ " mulher. É o pertencimento de classe que permite qualificar e compreender as pessoas na sua diferença (SOUZA, 2011: 1)

Nesta perspectiva, a vida é uma eterna disputa por distinção "com os outros", e esta disputa seria, essencialmente, de classe. Há uma construção social do "gosto", que faz com que determinados bens sejam considerados legítimos, distintos, e outros sejam considerados vulgares - um campo de batalha por legitimação e reprodução das práticas sociais (BOURDIEU, 2007). A ênfase na "naturalização do gosto" como perpetuação da dominação nos permite a compreender os jogos de distinção e pertencimento entre as classes, envolvendo a dimensão simbólica.

A ênfase nas dimensões culturais de classe aproximou Bourdieu do campo da Comunicação (GIRARDI JR., 2007) e é um dos autores mais citados na área de consumo no campo da comunicação, principalmente seu livro "A Distinção". Sua referencia também pode ser notada em outros livros considerados base nesta área, como Mary Douglas (2006) e Grant McCracken (2003).

Seja em qual linha teórica seguir, o que importa é que as classes assumem novas formas, sociais e discursivas - formas que são midiatizadas (GROHMANN, 2013a), pois as classes estão nas telenovelas, nas campanhas publicitárias, na conversação cotidiana dos sujeitos, nos institutos de pesquisa, nas práticas interacionais nas redes sociais, como uma "explosão midiatizada de classes" em todos os espaços.

Quais novas formas sociais adquiriram as classes sociais no Brasil nos últimos anos? Relaciona-se ao que se convencionou chamar de "nova classe média", considerado o fenômeno sociológico brasileiro recente mais importante, tornada uma marca política e publicitária utilizada por governo e mercados (GROHMANN, 2013a) e criticado por autores (SOUZA, 2010; POCHMANN, 2012; CHAUÍ, 2013) por não ser, de fato, nem "nova" nem "média". Este estrato, então, se refere à parcela da sociedade brasileira, devido às políticas sociais e de apoio ao crédito, que conseguiu, principalmente, ascender à "sociedade do consumo", a ter acesso aos direitos sociais, a entrar no universo "consumidor-cidadão" (CANCLINI, 2007).

$\mathrm{O}$ acirramento das disputas midiatizadas entre as classes brasileiras se dá a partir da mediação da política social do lulismo (SINGER, 2012), com políticas sociais compensatórias e o objetivo de tornar o Brasil um "país de classe média". Isso gerou um 
A orkutização das marcas: Disputas midiatizadas de distinção e pertencimento entre as classes sociais

de Alhen Rubens Silveira Damasceno e Rafael Grohmann

afastamento da "classe média tradicional" da base lulista, que se sentiu ameaçada e sem

perspectivas, gerando discursos midiatizados na internet com memes e hashtags, como o

\#ClasseMédiaSofre. É neste contexto onde se inserem as disputas materiais e simbólicas em torno das marcas e o fenômeno da "orkutização".

Este já é um indício das novas formas discursivas como se expressam as classes sociais no Brasil. Ana Lucia Enne (2011), a partir de um caminho bourdiano, comenta o uso das estratégias linguísticas na internet (no caso, o Orkut) usadas por grupos ligados a um consumo cultural considerado "desqualificado". A autora usa como exemplo as expressões "e daí?", "pronto, falei”, “confesso" como artimanhas discursivas de resistência ao preconceito e ao estigma pelo gosto, principalmente relacionado ao consumo musical, como pode ser visto abaixo:

\footnotetext{
"Eu gosto de Sertanejo, e dai??!" (300.600 membros) - "As pessoas falam que você é brega por ouvir Sertanejo? Não se deixe levar pelo preconceito".

"Eu vejo novela, e daí?!" (32.018 membros) - "Um espaço para quem gosta de novela, e não está nem aí para o que os outros dizem. A gente sim, sabe o que é se divertir...";

"Eu amo pagode e funk, e dai??" (101.476 membros) - "Comunidade feita pra você que quando está em uma festa e toca aquele pagode do tipo revelação... bokalokaa vc fica feliZ sem motivoo! (...) e que sempre tem uma babaca pra dize que pagode e funk é tosco e bom msm é iron maiden!";

"Eu ouço Bruno e Marrone, e dai" (53.942 membros) - "Essa é uma comunidade pras pessoas que são discriminadas por ouvirem Bruno e Marrone... Vc está cansado(a) de ser chamado de brega pelos seus amigos (...)".

"Gosto de banda Calipso, e dai?" (57.349 membros) - "Comunidade dedicada para todos aquelas pessoas que jah sofreram por gosta de Calypso!’(ENNE, 2011: 4)
}

Ou seja, as lutas midiatizadas entre as diferentes classes sociais por distinção e pertencimento, a partir de matrizes sociais e sígnicas, é uma questão a ser levada em consideração para o amadurecimento do pensamento sobre as relações e os processos de comunicação e consumo. As disputas em torno “orkutização das marcas" em um contexto de rolezinhos é um exemplo destas disputas.

\section{O QUE É ORKUTIZAÇÃO? O QUE É A ORKUTIZAÇÃO DAS MARCAS?}

Por que orkutização das marcas? Antes de tudo, vamos definir o que viria a ser o termo "orkutização". O termo vem da rede social criada pelo Google em 2004, Orkut, muito popular no mundo todo, mas que no Brasil foi uma explosão comunicacional, pois não só a parte mais elitista dos brasileiros teve acesso bem como as classes 
A orkutização das marcas: Disputas midiatizadas de distinção e pertencimento entre as classes sociais

de Alhen Rubens Silveira Damasceno e Rafael Grohmann

populares fizeram parte dessa rede social. Antes, o Orkut era todo em inglês e as pessoas convidavam umas as outras para ingressarem e fazerem parte do convívio social virtual, porém, com a tradução para a língua portuguesa e a abertura para todos os que pudessem acessar a rede de relacionamento sem um convite trouxeram uma quantidade gigantesca de novos adeptos, de novos internautas.

Com o aumento da participação popular na internet nos anos 2000 (em parte, justificada pela expansão do uso da internet pela população brasileira, em parte via lan houses), o Orkut, que antes era uma rede social de uma parte mais elitista da sociedade, se viu no olho do furacão quando as camadas populares entraram e tomaram de conta da rede social.

Então, as classes médias migraram para outra rede social: o Facebook. Lá não seria uma rede social orkutizada, pois o povo, supostamente, já teria a sua. Quando a rede se popularizou no Brasil, entre 2009 e 2010, houve a segunda onda de migração popular, que trouxe práticas consideradas "vulgares", "não-distintas" (BOURDIEU, 2007). Para as camadas mais ricas, aquelas camadas orkutizaram a rede social, ou seja, popularizaram o acesso com recados, fotos, com a criação de mais comunidades, tudo isso culminando com um "boom" dessa rede social que chegou a ser uma das mais populosas do mundo.

O termo "orkutização" e seus derivados se tornou sinônimo de popularização, um termo que traz consigo, uma carga negativa, de povão, de periferia, ou seja, daquilo que as classes mais ricas querem se afastar, não querem manter contato e quando um determinado lugar ou festa ou qualquer outro acontecimento social se populariza, dizem logo que o "lugar tal orkutizou", "a festa não é mais a mesma pois está orkutizada", e assim o termo se tornou um pejorativo para a diferenciação entre as classes sociais.

A questão da orkutização (e consequentemente, a relação com as marcas) envolve uma prática de distinção entre diferentes grupos sociais colocada por Georg Simmel e comentada por McCracken (2003): a teoria trickle-down.

Grupos sociais subordinados, segundo o princípio da imitação, buscam estabelecer suas reivindicações por um novo status adotando o vestuário dos grupos superiores. Estes, seguindo o princípio da diferenciação, respondem adotando novas modas. Renunciam a antigos marcadores de status e abraçam novos, abandonando aqueles à reivindicações dos grupos subordinados (McCRACKEN, 2003: 123).

E o que as marcas têm a ver com esse fenômeno? As marcas, hoje em dia, estão mais acessíveis. A ascensão da pretensa "nova classe média” fez com que o poder 
A orkutização das marcas: Disputas midiatizadas de distinção e pertencimento entre as classes sociais

de Alhen Rubens Silveira Damasceno e Rafael Grohmann

aquisitivo dos brasileiros aumentasse e isso trouxe outros desejos de consumo: um consumo da parte elitista que cada um de nós tem. Antes, os manuais de Marketing nos ensinava a respeito da pirâmide das necessidades de Maslow ${ }^{3}$. Hoje em dia, isso não faz mais sentido, não queremos mais a satisfação de uma necessidade completa para depois galgar para o próximo nível e assim por diante, queremos tudo agora, quero que a minha satisfação básica seja atendida, mas também quero o meu "ego" massageado pela satisfação pessoal, profissional, dentre outras.

Já que estamos falando de marca, Perez (2004) vem com uma definição de marca que a nós nos parece pertinente comentar. Ela nos fala que "a marca é uma conexão simbólica e afetiva estabelecida entre uma organização, sua oferta material, intangível e aspiracional e as pessoas para as quais se destina" (PEREZ, 2004:10).

Quando a autora nos fala que a marca é uma conexão simbólica e afetiva, temos a conclusão de que as marcas nos conferem um grau de satisfação. Ela nos entrega um mundo cheio de aspirações para adentrarmos e fazermos parte por meio dos valores que a marca encarna. Tal mundo que vivenciamos com a aquisição da marca pode nos remeter à jovialidade, à aventura, ao glamour, à beleza, à conquista, etc. Cabe a nós sabermos a quais mundos queremos pertencer e quais marcas nos possibilitam essa conexão simbólica.

Outro ponto importante na definição de marca a partir de Perez (2004) está no final do trecho destacado: "e as pessoas para as quais se destina". Sabemos que no mundo pós moderno, ou como chama Lipovetsky (2010), a sociedade do hiperconsumo, saber quem é o público-alvo da minha campanha publicitária está em processo de mutação, ou seja, nos anos de 1950-60 fazer esse tipo de planejamento e pesquisa para saber para qual público o meu produto se destina era mais preciso pois sabíamos que o meu produto/serviço poderia ser para mulheres das classes A e B, de 25 a 35, casadas e moradoras da cidade de São Paulo. Era tudo muito previsível, como se colocássemos todos encaixotados e eles estariam só esperando ser atingidos com a mensagem publicitária.

Hoje, as fronteiras das caixas foram derrubadas, o meu esforço comunicacional para uma marca de luxo pode ter como público a classe A, mas também a minha Classe C, que não é o público em questão, pode adquirir o produto. É o fenômeno que vem

\footnotetext{
${ }^{3}$ A hierarquia de necessidades de Maslow, também conhecida como pirâmide de Maslow, é uma divisão hierárquica proposta por Abraham Maslow, em que as necessidades de nível mais baixo devem ser satisfeitas antes das necessidades de nível mais alto. Cada um tem de "escalar" uma hierarquia de necessidades para atingir a sua auto-realização (CHIAVENATO, 2004).
} 
A orkutização das marcas: Disputas midiatizadas de distinção e pertencimento entre as classes sociais

de Alhen Rubens Silveira Damasceno e Rafael Grohmann

acontecendo: muitos dos produtos que antes eram só consumidos pela camada elitista,

hoje podem ser encontrados nas camadas mais populares, como foi o caso do tênis da marca Mizuno, cujo modelo Mizuno Wave Prophecy, que custa na faixa de mil reais feito para atletas e é um dos mais cultuados pelas camadas populares que utilizam, muitas vezes, o mesmo modelo sendo um de cada cor e isso é explicado pelo fato de gostar de um tênis caro, confortável, que traz em si toda uma aura de distinção, de pertencimento, de estar usando uma marca boa, de qualidade.

Lipovestsky (2010) em seu Livro A felicidade paradoxal nos faz uma síntese como é a relação das classes populares com as marcas. Para ele,

O culto contemporâneo das marcas traduz uma nova relação com o luxo e a qualidade de vida. Anteriormente, as classes populares e médias viam nas marcas de luxo bens inacessíveis que, destinados apenas à elite social, não faziam parte do seu mundo real, nem sequer dos seus sonhos. Produziu-se uma ruptura face a esta forma de cultura: a aceitação do destino social deu lugar ao "direito" ao luxo, ao supérfluo, às marcas de qualidade. A democratização do conforto, a consagração social dos referencias do prazer e do lazer minaram a tradicional oposição entre "gostos de necessidade" próprios das classes operárias e 'gostos de luxo' característicos das classes abastardas, bem como a moral da resignação e da austeridade. Na sociedade democrática de hiperconsumo, cada um tende a aspirar àquilo que há de melhor e de mais belo, a contemplar os produtos e as marcas de qualidade. Uma vez que os modos de socialização já não encerram os indivíduos em universos estanques, toda a gente considera ter direito à excelência e ambiciona viver melhor e nas melhores condições (LIPOVETSKY, 2010:41-42).

Por meio dessa passagem, podemos perceber claramente como está sendo marcada a sociedade brasileira. Com o aumento do poder aquisitivo de parte da população, as aquisições não só de bens materiais de primeira necessidade bem como de itens considerados supérfluos aumentou consideravelmente já que, se uma parte foi saciada (a aquisição de bens de consumo linha branca ${ }^{4}$ ), ou seja, a básica. Falta ainda saciar outra parte bem importante que vem a ser a aceitação, a visibilidade, a satisfação e o reconhecimento que vem acompanhado com a compra e usufruto dos produtos supérfluos que tem no consumo do luxo seu expoente máximo. Não é só a aquisição, mas também a experiência sinestésica que a marca propicia, todo um invólucro de proteção, de redes de associações positivas emocionais que a marca propicia ao consumidor.

\footnotetext{
${ }^{4}$ Eletrodomésticos da linha branca são produtos que além de serem itens básicos na maioria dos lares atualmente - como geladeiras, fogões, ar-condicionado, micro-ondas e máquinas de lavar, dentre outros. Hoje estes itens são produzidos com tecnologia que gera menos impacto ambiental como, por exemplo, a produção de refrigeradores com uso de gases que não lesam a camada de ozônio. Sendo assim, os eletrodomésticos da linha branca mais sustentáveis. Retirado do site: http://redeglobo.globo.com/globoecologia/noticia/2012/10/medida-economicafacilita-consumo-de-eletrodomesticos-da-linha-branca.html.
} 
A orkutização das marcas: Disputas midiatizadas de distinção e pertencimento entre as classes sociais

de Alhen Rubens Silveira Damasceno e Rafael Grohmann

Quando vemos um jovem adquirindo produtos de uma marca famosa, porém mais cara que as demais, temos que atentar aos simbolismos que a marca traz em si e que conexão ela faz com os seus usuários. Nessa questão de jovens de classes mais populares que se utilizam de marcas famosas para compor o seu visual, o que nos mais chama atenção é a vontade de inclusão em um determinado mundo, fazer parte de um segmento, ou seja, pertencer. Essa é a palavra-chave: pertencimento, a um estilo de vida, a uma sociedade cujos valores são regidos pelos processos de troca, aquisição e ressignificação de bens intangíveis que só a marca propicia aos seus usuários.

O logo não corresponde mais apenas a um sinal de reconhecimento daquele que adota o estilo de vida y e que pertence à cena z. Sob a compulsão generalizada à emissão, ele converte-se em um puro e simples sinal de identidade - em um sinal que faz com que eu esteja "aí". Não ter um logo significa de agora em diante ficar sem nome, se individualidade, sem pertencimento, em suma, perdido (TÜRCKE, 2010: 54).

E ainda vamos longe e dizemos que, não ter um logo que encarna toda a identidade e imagem de uma marca por meio dessa expressividade, é não ter a sensação da afetividade depositada no nosso imaginário de que pertencemos a um determinado grupo social. Tal afetividade que também está na definição de marca elucidada por Perez, acima citada, nos confirma o que Sodré (2006) nos fala em seu livro As estruturas sensíveis que os "jogos de vinculação dos atos discursivos às relações de localização e afetação dos sujeitos no interior da linguagem" (SÓDRE, 2006:10). Essa linguagem pode ser vinculada aos discursos midiatizados de pertencimento, de afetação e de distinção que a marca proporciona para os consumidores.

Spinoza nos fala que o desejo é o afeto que mais se alinha com "a própria essência do homem" (SPINOZA apud SILVA, 2013), como tal essência é característica humana, então o desejo, como afeto, de pertencer, de ser reconhecido é uma regra para os jovens, nos dias de hoje.

Porém, essa tentativa de pertencimento rege uma luta desigual entre as camadas mais ricas e as populares. Tal embate é revestido de preconceitos e desvalorizações, já que, se a marca cai no gosto popular ela é automaticamente rejeita pelos circuitos das classes mais abastadas, pois assim não haveria uma distinção imposta pelas marcas e a separação entre as classes tornando, assim, as fronteiras borradas e tais fronteiras livres não haveria mais uma distinção de quem é você e de quem sou eu na sociedade. 
A orkutização das marcas: Disputas midiatizadas de distinção e pertencimento entre as classes sociais

de Alhen Rubens Silveira Damasceno e Rafael Grohmann

A verdade é que, comprando esta ou aquela marca, o adolescente faz uma escolha que $o$ distingue do mundo de seus pais, afirma preferências e gostos que o definem, apropria-se de um código. Se o logotipo se reveste de uma tal importância, tal deve-se ao facto de permitir uma pertença reivindicada pelo indivíduo e já não uma pertença encarada como um destino social, familiar ou outro. É neste sentido que a compra de uma marca é vivida como a expressão de uma identidade simultaneamente clânica e singular. Exibindo esta marca em público, o adolescente identifica-se com ela, considerando-a como um emblema de sua personalidade. Por aqui podemos concluir que a oposição exagerada entre individualismo e "tribalismo"pós-moderno é perfeitamente artificial e enganadora: apesar da sua dimensão comunitária, a marca exibida é subjectivante e traduz, ainda que de forma ambígua, uma apropriação pessoal, uma procura de individualidade, bem como um desejo de integração no grupo dos pares, um eu que reivindica, aos olhos de todos, os símbolos da sua aparência (LIPOVETSKY, 2010:44).

\section{AS MARCAS E A ORKUTIZAÇÃO EM CONTEXTO}

Mas quais são as marcas mais cultuadas pelos jovens das camadas mais populares no Brasil atualmente?

Fig. 1 - Marcas mais cultuadas pela camadas mais populares.

Fonte: http://www.inteligemcia.com.br/139833/2014/01/23/f-biz-mapeia-10-pontosmais-importantes-para-entender-o-rolezinho/

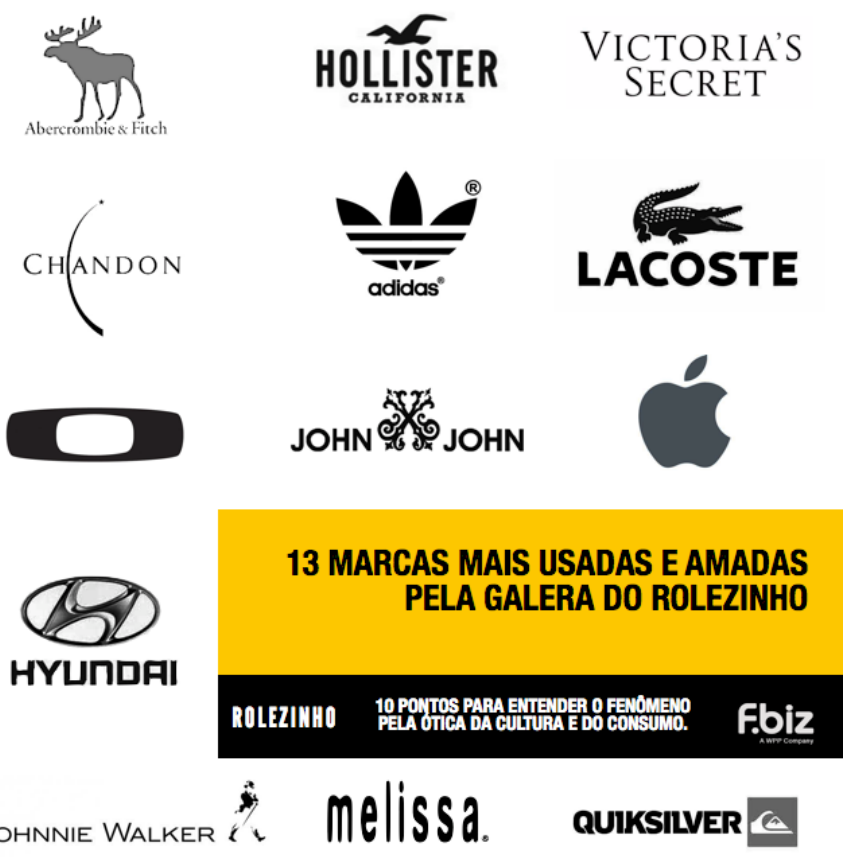

Algumas dessas marcas se tornaram mais cultuadas e adquiridas, principalmente, por causa do fenômeno chamado "Rolezinho" que, de acordo com Fígaro e Grohmann (2014: 9 ) "os rolezinhos são encontros marcados por jovens pela internet e tiveram 
A orkutização das marcas: Disputas midiatizadas de distinção e pertencimento entre as classes sociais

de Alhen Rubens Silveira Damasceno e Rafael Grohmann

início nos shoppings centers em São Paulo" e também pelo estilo musical Funk, mas precisamente, a sua vertente mais popular entre os jovens que vem a ser denominada como "Funk Ostentação". No Funk Ostentação, as marcas são cantadas como sinônimos de sucesso, de status, de realização, pois algumas letras evocam não só as condições que as marcas propiciam e sim a condição da luta entre as classes "patrão" x "funcionário", que são regidos pela maior aquisição das marcas de luxo. Quanto maior o luxo mais se aproxima do patrão e se distancia do funcionário.

As letras, muitas vezes, cultuam uma variação de marcas, dentre elas estão as de automóveis (Camaro, Audi, Veloster, a moto Suzuki Kawasaki), vai passando por roupas e acessórios de grife (Oakley, Lacoste, Louis Vuitton) e por bebidas caras (uísque Red Label, vodka Absolut, rum Big Apple, o espumante Chandon, dentre outros).

\author{
Eu sou patrão não funcionário \\ Meu estilo te incomoda \\ Só pego as melhores e ando sempre na moda \\ Bacana eu tiro é onda, olha olha olha só \\ O baile do Andara no Rio é o melhor
}

A nossa roupa é da Ed Hardy, Rio Local ou da Armani
O bonde tem um Audi, um Veloster e um Megane
Eu to portando a Captiva com som de duzentos mil
Estilo panicat me deu mole quando viu [...]
(Trecho da música "Eu sou patrão não empregado" do Mc Menor do Chapa)

Como nos mostra a letra da música, as marcas que antes eram sinônimos de status e distinção e só uma pequena parcela da sociedade poderia ter acesso e que hoje é exaltada e cantata nos bailes Funks, são usadas para encontros como os propostos pelos "rolezinhos". Outros dois exemplos são trazidos por outros ícones do Funk Ostentação. Na música "Na pista eu arraso", MC Guime diz: "de Ranger Rover Evoke / na pista eu arraso / no Instagram um close / ela comenta 'eu caso'/e aqui são vários casos/ pra gente desenrolar/ camarote fechado/ champanhe pra estourar". Outra música que pode ser identificada com o "funk ostentação", mas vindo do Rio de Janeiro, é o de MC Marcelly, com a música "Bigode Grosso": "na festa não vai ter cerveja/ mas pra nós ficar sussu/ vai ter muito uísque, 10 freezer de Red Bull/ liberado pras meninas pro negócio ficar bom/ vai ter muita Amarula e muito Chandon".

Ou seja, isso culmina com a popularização das marcas e um endeusamento por parte daqueles que passaram a adquiri-las, pois antes as classes mais ricas tinham seus cultos como uma seita secreta em que poucos eram os escolhidos para fazer parte do 
A orkutização das marcas: Disputas midiatizadas de distinção e pertencimento entre as classes sociais

de Alhen Rubens Silveira Damasceno e Rafael Grohmann

mundo simbólico e produtor de sentidos que só a marca permite evocar e hoje com a "orkutização" das marcas, o culto foi alargado e já não tem mais os escolhidos, os poucos de antes se tornou uma legião de fãs que cultuam, vivem e se apropriam das afeições que a marca permite expor para os seus consumidores/exaltadores. Como nos fala Lipovetsky,

Mesmo entre os jovens, o imaginário de igualdade democrática teve o seu impacto, levando o indivíduo a recusar-se a apresentar uma imagem de si próprio marcada por uma inferioridade desvalorizante. É, sem dúvida, por isso que a sensibilidade às marcas é tão ostensiva nos meios desfavorecidos. Através de uma marca apreciada,o jovem sai da impersonalidade; o que ele quer mostrar não é uma superioridade social, mas a sua participação inteira e igual nos jogos da moda, da juventude e do consumo. Bilhete de entrada para o modelo de vida "moda", é o receio do desprezo e da rejeição dolorosa por parte dos outros que activa a nossa obsessão pelas marcas (LIPOVETSKY, 2010:43).

Dentro deste jogo de "pertencimento" e "distinção", as marcas de grife estariam com vergonha de seus clientes populares, de acordo com o Instituto Data Popular (UOL ECONOMIA, 2014). Segundo o presidente do Instituto, Renato Meirelles, algumas empresas o procuraram dizendo: "minha marca está virando letra de música, febre na periferia e não quero estar associado a esse pessoal". Meirelles afirma instruir os presidentes das empresas a procurar saber os motivos de essas pessoas buscarem as marcas. Isso nos remete à questão da pesquisa de mercado discutida acima a partir da dificuldade de se compreender os públicos das marcas.

De certa maneira, isso evidencia como as marcas estão perdidas em seus processos comunicacionais e como há, nas marcas de elite, uma preocupação de “distinção", estigmatizando as classes populares e a popularização de produtos e serviços. Isto é, esse contexto reafirma os processos midiatizados de lutas e ajuda a confirmar valores ideológicos conservadores em circulação, como mostram os comentários do portal Terra analisados por Fígaro e Grohmann (2014).

Outro exemplo desta "reação conservadora" à "orkutização das marcas" é a peça publicitária de mídia impressa da companhia aérea Swiss, veiculada na revista Lifestyle, em outubro de 2013, como pode ser conferida abaixo: 
A orkutização das marcas: Disputas midiatizadas de distinção e pertencimento entre as classes sociais

de Alhen Rubens Silveira Damasceno e Rafael Grohmann

Fig. 2 - Peça de mídia impressa página dupla - Swiss

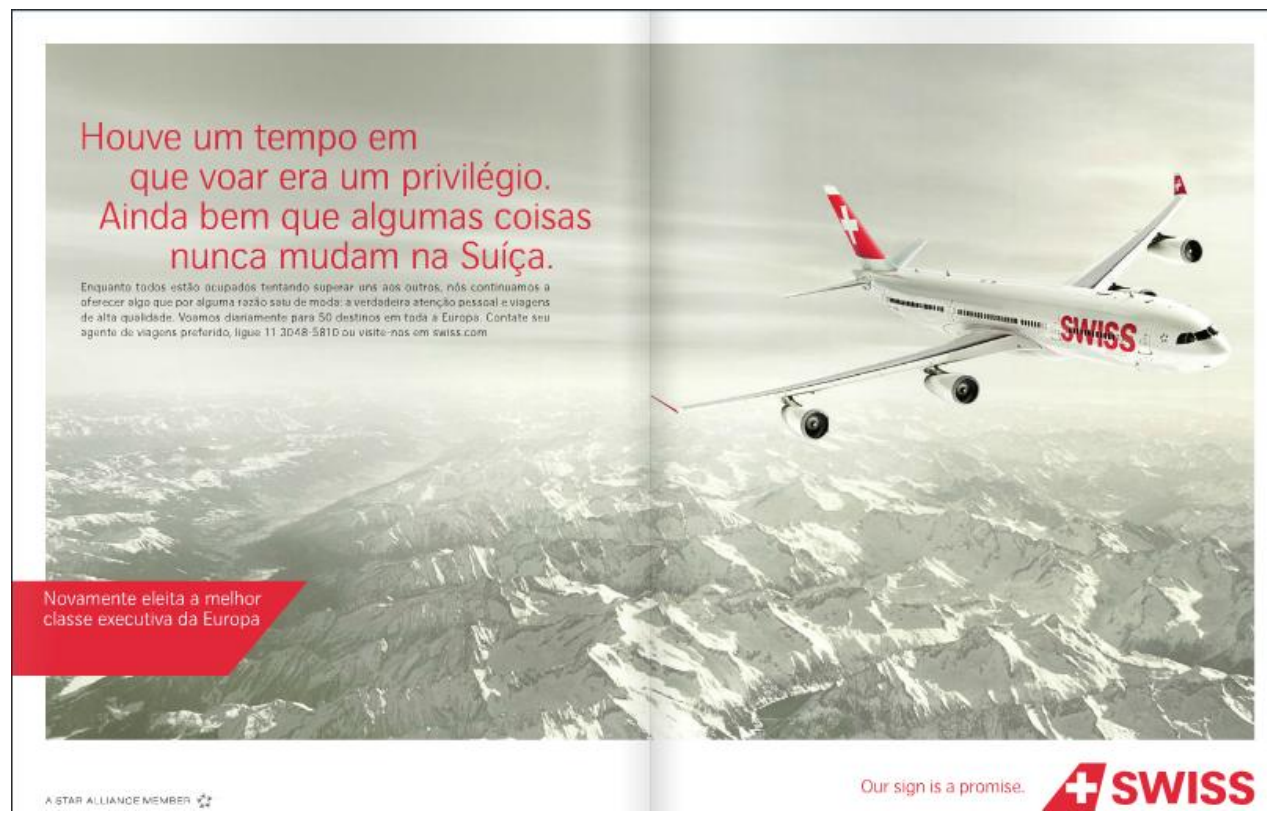

Reforça-se, nesta peça, a naturalização do privilégio e a legitimação das desigualdades pelas classes médias brasileiras, como mostra Jessé Souza (2010), com a segregação dos espaços sociais. Remete-nos a enunciados como: "o aeroporto virou rodoviária", no sentido midiatizado da "orkutização dos aeroportos", antes espaço privilegiado das elites, enquanto a rodoviária seria o "lugar dos pobres". A peça da companhia Swiss dialoga com a elite brasileira neste contexto de lulismo (SINGER, 2012), onde ela diz "sofrer" (\#ClasseMédiaSofre).

Portanto, a partir da questão da "orkutização das marcas" e a busca por distinção das marcas de elite, podemos observar como o conceito de "classe social" não está morto na comunicação, enquanto discurso e prática social em circulação. As disputas midiatizadas entre as classes sociais por distinção (por parte das elites) e pertencimento (por parte das camadas populares) nos remete a esta frase de Raymond Williams, datada de 1958, onde o britânico já falava sobre as "posses" e a vida cotidiana dos sujeitos a partir do contexto das classes. As classes trabalhadoras não deixam de existir somente por consumir roupas da Lacoste e da Abercombrie.

A classe trabalhadora não se torna burguesa por possuir novos produtos da mesma maneira que os burgueses não deixam de ser burgueses à medida que os objetos que eles possuem passam a ser de um tipo diferente. (...) A inveja que um operário tem do homem de classe média, não é um desejo de ser aquele homem, mas sim de ter o mesmo tipo de posses. (...) A grande maioria dos trabalhadores ingleses só quer o padrão material da classe média, mas, quanto ao resto, quer continuar sendo ela mesma (Williams, 2011 [1958]: 347-348). 
A orkutização das marcas: Disputas midiatizadas de distinção e pertencimento entre as classes sociais

de Alhen Rubens Silveira Damasceno e Rafael Grohmann

\section{REFERÊNCIAS BIBLIOGRÁFICAS}

ANTUNES, Ricardo. O Caracol e sua Concha: ensaios sobre a nova morfologia do trabalho. São Paulo: Boitempo, 2005.

BENJAMIN, Walter. A Obra de Arte na Época de Sua Reprodutibilidade Técnica. Porto Alegre: Zouk, 2012.

BOLTANSKI, Luc; CHIAPELlO, Ève. O Novo Espírito do Capitalismo. São Paulo: Martins Fontes, 2009.

BOURDIEU, Pierre. A Dominação Masculina. São Paulo: Bertrand Brasil, 1999

BOURDIEU, Pierre. A Distinção. São Paulo: Edusp, 2007.

CANCLINI, Néstor García. Consumidores e Cidadãos: conflitos multiculturais da globalização. Rio de Janeiro: Ed. UFRJ, 2007.

CHAN, Tak Wing (org.). Social Status and Cultural Consumption. Cambridge: Cambridge University Press, 2010.

CHAUÍ, Marilena. Uma nova classe trabalhadora. In: SADER, Emir (org.). Dez anos de governos pós-neoliberais no Brasil. São Paulo: Boitempo, 2013: 123-134.

CHIAVENATO, Idalberto. Introdução à teoria geral da administração. Rio de Janeiro: Campus, 2007.

DOUGLAS, Mary. O Mundo dos Bens: para uma antropologia do consumo. Rio de Janeiro: Ed. UFRJ, 2006

EAGLETON, Terry. Marx estava certo. Rio de Janeiro: Nova Fronteira, 2012.

ENNE, Ana Lúcia. "E daí?”, “pronto, falei!”, “confesso": artimanhas discursivas de qualificação e desqualificação do gosto e da distinção. In: Congresso Internacional de Comunicação e Consumo (Comunicon) - 2011. São Paulo: Escola Superior de Propaganda e Marketing (ESPM), 2011: 1-14

FIGARO, Roseli; GROHMANN, Rafael. Lutas de Classes e os 'Rolezinhos': uma abordagem na perspectiva dos Estudos de Recepção. In: XXII Encontro Encontro da Compós 2014 - Belém/PA. Anais da Compós 2014, 2014.

GIRARDI JR., Liráucio. Pierre Bourdieu: questões de sociologia e comunicação. São Paulo: Annablume, 2007.

GROHMANN, Rafael. A Midiatização da "Nova Classe Média": identidades discursivas na Revista IstoÉ Dinheiro. Anais do Congresso Internacional de 
A orkutização das marcas: Disputas midiatizadas de distinção e pertencimento entre as classes sociais

de Alhen Rubens Silveira Damasceno e Rafael Grohmann

Comunicação e Consumo (Comunicon) - 2013. São Paulo: Escola Superior de Propaganda e Marketing (ESPM), 2013a.

GROHMANN, Rafael. O conceito de classe social no marxismo: correntes e atualidade. Cadernos de Pesquisa Interdisciplinar em Ciências Humanas. V. 14, n. 105: 3$18,2013 b$.

LIPOVETSKY, Gilles. A Felicidade Paradoxal. Lisboa: Edições 70, 2010

LOSURDO, Domenico. La Lotta di Classe: una storia politica e filosofica. Roma-Bari: Laterza, 2013.

MATTELART, Armand; SIEGELAUB, Seth (org). Communication and Class Struggle: vol I - capitalism, imperialism. New York: International General, 1979.

McCRACKEN, Grant. Cultura e Consumo: novas abordagens ao caráter simbólico dos bens e das atividades de consumo. Rio de Janeiro: Mauad, 2003

MURDOCK, Graham. Comunicação Contemporânea e Questões de Classe. Matrizes. Ano 2, n. 2: 31-56, 2009.

PEREZ, Clotilde. Signos da Marca: expressividade e sensorialidade. São Paulo: Pioneira Thompson Learning, 2004.

POCHMANN, Márcio. Nova Classe Média? - O trabalho na base da pirâmide social brasileira. São Paulo: Boitempo, 2012

SANTOS, José Alcides Figueiredo. Estruturas de Posições de Classe no Brasil. Belo Horizonte: Ed. UFMG, 2002.

SILVA, Wagner Souza e. Narrativas fotográficas confessionais e a estética da afetividade. Anais do XXXVI Congresso Brasileiro de Ciências da Comunicação (INTERCOM). Manaus, 2013.

SINGER, André. Os Sentidos do Lulismo: reforma gradual e pacto conservador. São Paulo: Companhia das Letras, 2012.

SODRÉ, Muniz. As estruturas sensíveis: afetos, mídia e política. Petrópolis: Ed. Vozes, 2006.

SOUZA, Jessé. Os Batalhadores Brasileiros: nova classe média ou nova classe trabalhadora? Belo Horizonte: Ed. UFMG, 2010.

SOUZA, Jessé. Doença Social (Entrevista ao Jornal Estado de Minas). Caderno Pensar - Estado de Minas. Belo Horizonte, 15 jan. 2011: 1 
A orkutização das marcas: Disputas midiatizadas de distinção e pertencimento entre as classes sociais

de Alhen Rubens Silveira Damasceno e Rafael Grohmann

THOMPSON, Edward Palmer. A Formação da Classe Operária Inglesa. Vol I. Rio de Janeiro: Paz e Terra, 1987.

TÜRCKE, Christoph. Sociedade excitada: filosofia da sensação. Campinas: Editora Unicamp, 2010.

WEBER, Max. Classe, status e partido. In: VELHO, Otávio; PALMEIRA, Moacir; BERTELLI, Antonio (org.). Estrutura de Classes e Estratificação Social. Rio de Janeiro: Zahar, 1966.

WILLIAMS, Raymond. Cultura e Sociedade: de Coleridge a Orwell. Petrópolis: Vozes, 2011.

Artigo submetido: 18/05/2014

Artigo aprovado: 03/06/2014 